\title{
Recent changes in ichthyoplanktonic assemblages of the eastern English Channel
}

Di Pane Julien 1, 2, Koubbi Philippe 1,3, Giraldo Carolina 1, Lefebvre Valerie ${ }^{1}$, Caboche Josselin ${ }^{1}$, Marchal Paul ${ }^{1}$, Loots Christophe ${ }^{1,}{ }^{*}$

1 IFREMER, Channel and North Sea Fisheries Research Unit, 150 quai Gambetta, F-62321 Boulognesur-Mer, France

2 BOREA, Museum national d'histoire naturelle, Sorbonne Université, Université de Caen Normandie, Université des Antilles, CNRS, IRD, 43 rue Cuvier, 75005 Paris, France

3 UFR 918 Terre Environnement et Biodiversité, Sorbonne Université, 4, place Jussieu, F-75252 Paris Cedex 05, France

* Corresponding author : Christophe Loots, email address : $\underline{\text { Christophe.Loots@ifremer.fr }}$

\begin{abstract}
:
ish assemblages vary through time in both abundance and diversity, often due to changes in climate. The potential consequences of these changes on the larval phase need to be considered. In the Eastern English Channel, fish larvae of 30 taxa, from surveys conducted during spring in the nineties and in 2017 with bongo nets, were used to investigate seasonal and interannual changes in larval assemblages with different statistical tests and multivariate analyses (Outlying Mean Index, Principal Coordinate Analysis and variance partitioning). The major change observed was significant lower abundances in 2017 (in April and May) compared to the nineties. Most of the dominant taxa were two to three-fold less abundant in 2017 than the 1990s. We suggest that the reduced larval abundances in 2017 could be a consequence of lower adult abundances in the area from a switch from a colder to a warmer phase of the Atlantic Multidecadal Oscillation.
\end{abstract}

\section{Highlights}

Larval assemblages were dominated by ten species. Overall abundances and diversity increased across the spring season. Larval abundances were significantly lower in 2017 compared to the nineties. - Several larval and adult fish species responded similarly to a shift in the AMO.

Keywords : fish larvae, temporal variations, Atlantic Multidecadal Oscillation, Outlying Mean Index, variance partitioning, English Channel 


\section{Introduction}

In the context of global change, fish communities hid a undergone shifts in both abundance and species composition (Reid et al., 2001; Harmin et al., 2013). In the Eastern English Channel (ECC), Auber et al. (2015, 2017, noted an increase in sea surface temperature at the end of the nineties to explain the isficant decrease in fish abundance at the community level. However, the underlying $\mathrm{r} e \mathrm{c}$ lanism remains unclear and the potential role of the larval phase in these chanr es as not been investigated. In spring, the spatial distribution of larval assemblages on se southern side of the EEC is influenced by a coastal front (Grioche and Koubbi, 1997) $\mathrm{r} / \mathrm{h} / \mathrm{n}$ varies according to the winds and the megatidal regime of the EEC. The c Jas al waters along the French coast differ in terms of hydrobiological characteristic ( $1 . \mathrm{g}$. salinity, turbidity, phytoplankton, zooplankton) from the central waters (Brylin ${ }^{1} \mathbf{i}$ n $_{\perp}$ Lagadeuc, 1990). Most of the fish larvae in this area are distributed according to this coastal/offshore separation (Grioche et al., 1999, 2000, 2001; Koubbi et al., 2006) with younger larvae in the central waters and older larvae closer to the southern coast. On the northern side, while observations are more limited, the absence of this frontal structure leads to a different configuration in larval assemblages (Koubbi et al., 2006).

The crucial role of the larval phase in fish population dynamics has been widely recognised (see Miller and Kendall, 2009; Somarakis et al., 2018). Fish larvae are influenced by fluctuations of abiotic and biotic conditions including species interactions such as 
predation, competition and food availability (Miller and Kendall, 2009; Houde, 1987). Ichthyoplanktonic studies, thanks to oceanographic surveys, aim to acquire essential data on fish early life stages in terms of abundances, diversity, spatio-temporal distributions and physiological condition. These data can be used to compute recruitment indices as well as indicators of spawning dynamics and changes in the ecosystem that can be integrated within ecosystem models. While spring surveys were regularly programmed during the nineties on the southern EEC, no survey was conducted from 1999 to 2017 . The completion of three new surveys conducted in 2017 in the same area of the EEC throus:out the springtime allowed comparisons of larval assemblages between the nineties an $1\left\llcorner^{\top} 1 /\right.$.

The main objective of this paper is to comt are fish larvae assemblages in terms of species composition between these two contrastiog periods of sea surface temperature. In particular, the role of different sources of v. riation, including spatial, seasonal, inter-annual and environmental effects, on the fluctuation of larval assemblages has been investigated.

\section{Materials and Methods}

\subsection{Sampling strategy}

Data came from 1 - nent ichthyoplanktonic surveys that were conducted in the EEC, especially in its southern , art, between March and June in 1993, 1994, 1995, 1999 and 2017 (Table 1). Coastal-offshore sampling was primarily performed between the Bay of Seine and Belgium and between the Isle of Wight and the Thames estuary (Figure 1). At each of the 308 stations where ichthyoplankton was sampled, environmental variables were recorded. 
Table 1: List of the sampling surveys. Dates of sampling and number of stations are indicated.

\begin{tabular}{cccc}
\hline Survey & Start & End & $\begin{array}{c}\text { Number of } \\
\text { stations }\end{array}$ \\
\hline SIPMO 4 & $01 / 04 / 1993$ & $01 / 04 / 1993$ & 8 \\
SIPMO 5 & $14 / 05 / 1993$ & $14 / 05 / 1993$ & 8 \\
SIPMO 6 & $25 / 06 / 1993$ & $25 / 06 / 1993$ & 8 \\
SIPCOI & $28 / 04 / 1994$ & $29 / 04 / 1994$ & 21 \\
SIPCOII & $27 / 05 / 1994$ & $31 / 05 / 1994$ & 20 \\
SIPCOIII & $23 / 06 / 1994$ & $27 / 06 / 1994$ & 21 \\
REISEI & $11 / 04 / 1995$ & $13 / 04 / 1995$ & 45 \\
REISEII & $02 / 05 / 1995$ & $04 / 05 / 1995$ & 48 \\
SIPCOIV & $24 / 05 / 1995$ & $26 / 05 / 1995$ & 21 \\
BCD & $27 / 04 / 1999$ & $01 / 05 / 1999$ & 32 \\
REIVE1 & $23 / 03 / 2017$ & $30 / 03 / 2017$ & 26 \\
PHYCO & $21 / 04 / 2017$ & $29 / 04 / 20.7$ & 24 \\
REIVE2 & $05 / 05 / 2017$ & $12 / 05 /{ }^{\circ} 117$ & 26 \\
\hline
\end{tabular}

\subsection{Fish larvae sampling and identification}

Fish larvae were sampled using a he lgo net (60 cm diameter, Smith, 1977) fitted with either two $500 \mu \mathrm{m}$ nets or with one $5 \iota^{?}$ and one $330 \mu \mathrm{m}$ net. The net was deployed at two knots through a double oblique-tr-y $\because$ cween the surface and five meters above the seabed during at least 10 minutes. T a fuiered volume of seawater was estimated using a digital flowmeter fixed at the entrv $\iota^{c} r$ ach net. For this study, only the first net of $500 \mu \mathrm{m}$ mesh size was considered. The cu 'tent of the net was fixed in a buffered-formalin seawater solution for later identification at the laboratory. Fish larvae were sorted under a stereomicroscope and identified at the species, genus or family levels according to Russell (1976). Abundances of each taxon (ind.100 $\mathrm{m}^{-3}$ ) were calculated using the filtered volume of seawater.

Figure 1: Location of sampling stations. Colors correspond to the three areas used for the Kruskal-Wallis test $($ grey $=$ area $A ;$ black $=$ area $B$ and red $=$ area $C)$. Open circles are stations which were not allocated to an area. Coastal and central waters, separated by the front are represented. 

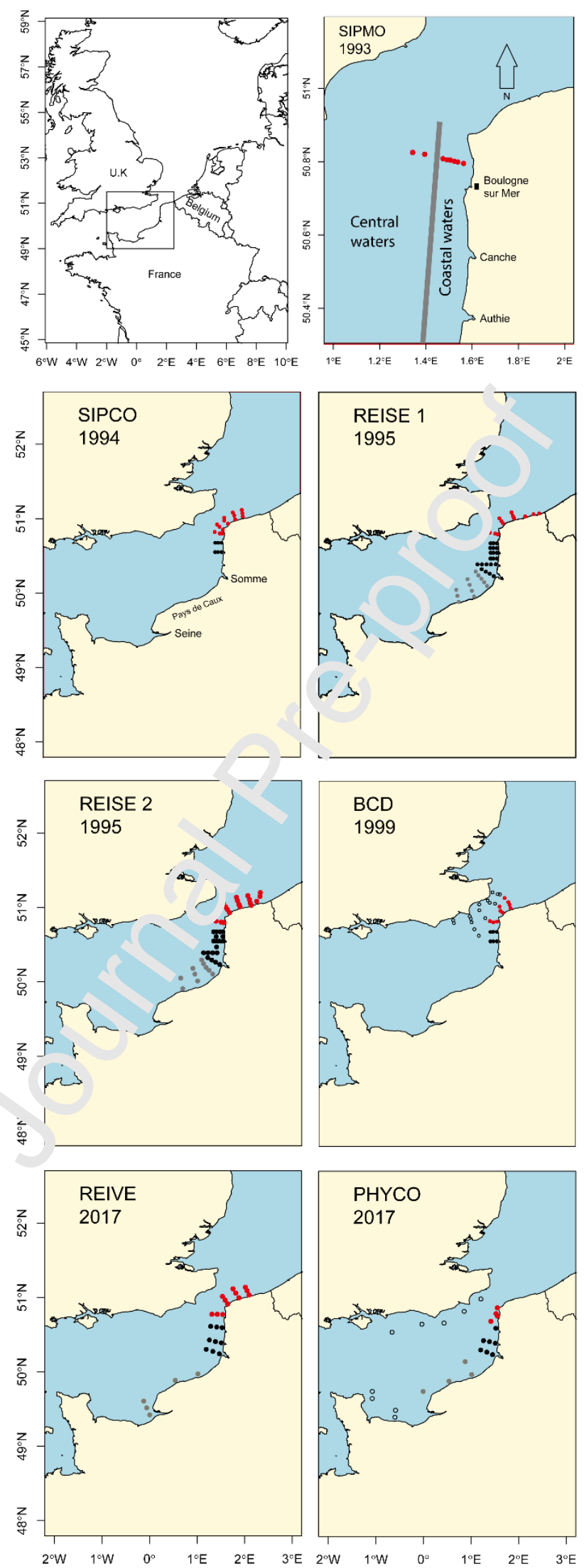


\subsection{Environmental variables}

Vertical profiles of temperature $\left({ }^{\circ} \mathrm{C}\right)$ and salinity were recorded using a Seabird SBE 19 CTD (Conductivity Temperature Depth) profiler. Geographical factors such as the distance to the coast and to the nearest estuary were post-calculated with a geographic information system (ArcMap 9.2 from ESRI). Bedstress $\left(\mathrm{N} \cdot \mathrm{m}^{-2}\right)$ and depth (m) were also mapped.

\subsection{Statistical analyses}

Of the 80 taxa encountered, statistical analyses were pu formed on the 30 taxa that were present in at least five percent of all the stations sa m, led. Abundances were logtransformed $(\log [\mathrm{x}+1])$. Statistical and multivariate a. alyses were applied under the $\mathrm{R}$ software (R Core Team, 2018) and the threshold of sicusicance for all analyses was set at an alpha of 0.05 .

Annual differences in total lar $\urcorner^{\prime}$ abundance were tested using non-parametric Kruskal-Wallis tests (Hollander and WOA $^{2}$. 1973) performed on April and May surveys. Only taxa accounting for $80 \%$ of the " $^{+}$il abundance were analysed. The southern side of EEC between the Bay of Seine and 2 lgium, i.e. the common area for all surveys, was also divided into three areas based s.m sunpling regularity between years and larval composition from previous studies (Grioche at al., 2001; Koubbi et al., 2006): the Seine estuary to the south of the Somme estuary along the Pays de Caux (A), the three estuaries (Somme, Authie and Canche) of the Opale coast (B) (the most regularly sampled between years) and from Boulogne-sur-Mer to Belgium (C, Figure 1). Monthly and annual quantiles of abundances were also calculated for taxa that accounted for $80 \%$ of the total abundance from all surveys.

A Principal Coordinates Analysis (PCoA) was used to compare the similarity of larval assemblages between all samples and surveys. PCoA is the generalization of the PCA to any 
distance matrix (Legendre and Legendre, 2012). Here, the Bray Curtis distance was used to calculate the dissimilarity matrix from the fauna matrix.

The collinearity between the environmental and geographical variables was assessed using a Pearson correlation test. When two variables had a significant correlation coefficient higher than or equal to 0.6 , one of the two variables was removed.

Taxa-environment relationships were studied using an Outlying Mean Index analysis (OMI, Dolédec et al., 2000) performed using all surveys. Te. nerature, salinity, distance to the coast and to the nearest estuary, bedstress, depth and la itur e were used as explanatory variables. This method is a co-inertia analysis betweer an environmental data matrix, in the form of a PCA, and a fauna data matrix. OMI invesisat ss the relevance of the environmental factors by separating taxa according to the cha ar ie istics of their habitat. Average conditions are represented by the origin of the axer. C Ml unalysis provides for each taxon a marginality index (called OMI) that represents th a distance between the average conditions of the habitat used by the taxon and the average sacions over all of the stations (i.e. axes origin). It also provides a tolerance index ( $\mathrm{l} \mathrm{L}^{1}$, which is the spatial variance of the niche across environmental conditions. Trxa Living low OMI and high Tol values are represented close to the axes origin and $\left.a^{\curvearrowright} \iota\right\urcorner n s$ Jered ubiquitous (i.e. they occupy a wide range of environmental conditions). Conversely, ingh OMI and low Tol values represent marginal or specialist taxa. Significance of the OMI values was tested by a Monte Carlo permutation test (999 permutations).

Influence of the environment, space and time on larval composition variation was investigated using a variance partitioning approach (Mood, 1971; Peres-Neto et al., 2006) as proposed by Legendre and Legendre (2012). Using all the surveys and their data available, the aim of this approach was to calculate the amount of variance explained in the fauna matrix by 
each of the set of explanatory variables once the effect of the other variables (called covariables) had been removed. It also permitted calculations of the amount of explained variation that was shared by the different variables. For the environment, temperature and salinity were used as the explanatory variables. For time and space, variables were built using Moran's eigenvector maps (MEM) approach which was proposed by Dray et al. (2006) based on Borcard and Legendre (2002). The principle of MEM is the construction of a series of variables representing either spatial (Loots et al., 2010) or temporal (Baho et al., 2015) structures. Three sets of variables: spatial, annual and seasonal. we : created. For the seasonal and annual variables, the mean day of the month and the $y u^{\wedge} \mathrm{r}$ of each survey were used to calculate the Euclidean distance matrix. For the spatia variables, the distance matrix was calculated on the latitude and corrected longitude (n ngitude* $\cos [($ latitude*Pi)/180]) of the sampling stations (Loots et al., 2010). Distanc a nat.ices were then truncated by changing all values above a threshold (i.e. the highe $d$ stance between two neighbors) to four times that threshold, so that all the points remaned connected. Eigenvectors (MEMs) with positive eigenvalues were extracted from a $P(\cap \perp$ performed on each truncated matrix. A redundancy analysis (RDA) was then per' rrmed between the detrended table and all positive MEMs variables from each set $\iota^{f}$ variables before checking significance by a Monte-Carlo permutation test (999 neınutations). Significant MEMs variables were selected using a forward selection based on their adjusted R-square ( $\mathrm{R}^{2} \mathrm{adj}$ ) with regard to the fauna data matrix, which was linearly detrended beforehand according to latitude and corrected longitude (Blanchet et al., 2008; Miller and Farr, 1971). The forward selection performs a Monte Carlo permutation test (999 permutations) on each variable and stops when either the $\mathrm{R}^{2} \mathrm{adj}$ threshold is reached when adding a new variable or when the added variable is not significant. The variable inflation factor (VIF; Gross, 2003) was computed for each set of variables in order to examine the collinearity between environment, space and time (James et al., 2013). 
This method provides the ratio of variance between a model containing all variables and a model with a single variable. Only variables with a VIF below 15 were kept. Finally, variation partitioning was performed to quantify the part of variation in the larval assemblages explained by each set of variables (Anderson and Cribble, 1998), as well as the amount of explained variation shared by the different variables. The significance of the variation explained by each set of variables was assessed by a Monte Carlo permutation test (999 permutations).

\section{Results}

Table 2: List of the most frequently found fish la va' + axa between 1993 and 2017 in the sampling area. Codes used in fig .... v re also indicated.

\begin{tabular}{|c|c|c|}
\hline Scientific name & Common na.ne & Code \\
\hline Ammodytidae & San $e^{\prime \prime}$ & Amm spp \\
\hline Buglossidium luteum & Sriericie & Bug lut \\
\hline Callionymidae & L 'agunets & Cal spp \\
\hline Clupea harengus & $\overline{A_{i}^{\prime \prime}}$-ntic herring & Clu har \\
\hline Cottidae & Cottids & Cot spp \\
\hline Dicentrarchus labrax & European bass & Dic lab \\
\hline Diplecogaster bimaculata & in o-spotted clingfish & Dip bim \\
\hline Echiichthys vipera & Lesser weever & Ech vip \\
\hline Gadidae & Gadids & Gad spp \\
\hline Gobiidae & Gobies & Gob spp \\
\hline Labrus bergvita & Ballan wrasse & Lab ber \\
\hline Limanda lim $\overline{n d a}$ & Common dab & Lim lim \\
\hline Liparis lipa. ${ }^{-{ }^{\prime}}$ & Common seasnail & Lip lip \\
\hline Liparis moı ingui & Montagu's seasnail & Lip mon \\
\hline Lotidae & Lings & Lot spp \\
\hline Merlangius merlangus & Whiting & Mer mer \\
\hline Micrenophrys lilljeborgii & Norway bullhead & Mic lil \\
\hline Microchirus variegatus & Thickback sole & Mic var \\
\hline Platichthys flesus & European flounder & Pla fle \\
\hline Pleuronectes platessa & European plaice & Ple pla \\
\hline Sardina pilchardus & European pilchard & Sar pil \\
\hline Scophthalmus maximus & Turbot & Sco max \\
\hline Scomber scombrus & Atlantic mackerel & Sco sco \\
\hline Solea solea & Dover sole & Sol sol \\
\hline Sprattus sprattus & European sprat & Spr spr \\
\hline Taurulus bubalis & Longspined bullhead & Tau bub \\
\hline
\end{tabular}




\begin{tabular}{ccc}
\hline Trachurus trachurus & Atlantic horse mackerel & Tra tra \\
\hline Trisopterus luscus & Pouting & Tri lus \\
\hline Trisopterus minutus & Poor cod & Tri min \\
\hline Trisopterus & Trisopterus & Tri spp \\
\hline
\end{tabular}

Kruskal-Wallis tests performed on total abundances between April and May for the three areas indicated that abundances in 2017 were significantly different from those in the nineties except for April in area C and with 1999 in area B (Table 3). There were also differences within the nineties, in particular between 1999 ani the other years for April in area A and B. The only difference among 1993, 1994 and 1.95 vas found in April in area C between 1993 and 1994.

Table 3: results of the Kruskal-Wallis tests com -arison between years and areas (see figure 1) for April ( nr. May surveys.

\begin{tabular}{|c|c|c|c|}
\hline \multirow{2}{*}{ Area } & Years & \multicolumn{2}{|c|}{ p-value } \\
\hline & comparison & April & May \\
\hline$A$ & $1995-20: 7$ & $<0.01$ & $<0.01$ \\
\hline \multirow{6}{*}{$B$} & $1994-19,25$ & 0.27 & 0.99 \\
\hline & $\overline{1994-1} \bar{\jmath} 19$ & $<0.01$ & - \\
\hline & $\overline{199} \cdot-2 \overline{C^{1}} 7$ & $<0.01$ & $<0.01$ \\
\hline & $1 0 \longdiv { 3 - i 9 9 9 }$ & $<0.01$ & - \\
\hline & 12952017 & $<0.01$ & $<0.01$ \\
\hline & $9909-2017$ & 0.95 & - \\
\hline \multirow{10}{*}{ C } & $993-1994$ & $<0.05$ & 0.96 \\
\hline & $1993-1995$ & 0.09 & 0.96 \\
\hline & 1993-1999 & 0.38 & - \\
\hline & 1993-2017 & 0.99 & $<0.01$ \\
\hline & 1994-1995 & 0.98 & 0.99 \\
\hline & 1994-1999 & 0.98 & - \\
\hline & 1994-2017 & 0.37 & $<0.01$ \\
\hline & 1995-1999 & 0.97 & - \\
\hline & $1995-2017$ & 0.59 & $<0.01$ \\
\hline & $1999-2017$ & 0.97 & - \\
\hline
\end{tabular}

Larval abundances per taxa were summarized by year and month (Figure 2). Of the 30 taxa initially used in the analysis, ten of them accounted for $80 \%$ of the cumulative abundance 
by month or year. These included two clupeids (sprat and herring), dragonets, gobies, sandeels, horse mackerel, whiting and three flatfishes (solenette, dab and sole). Sprat was the most abundant taxa in all years and months, accounting for $40 \%$ to $64.5 \%$ of the total abundance, followed by dragonets, gobies and sandeels. From 1993 to 1999, four or five taxa accounted for $80 \%$ of the total abundance and six in 2017 due to lower taxa abundances.
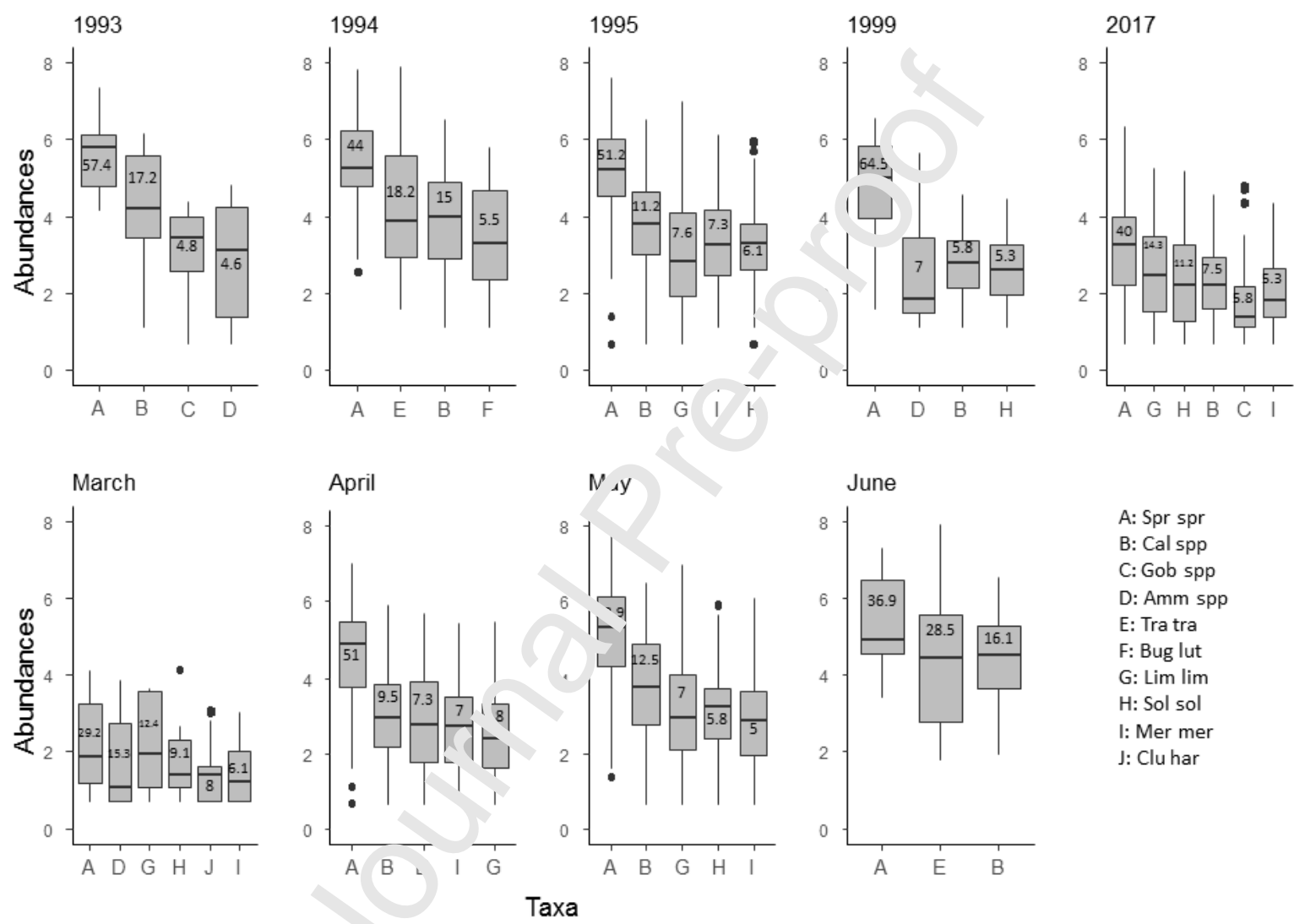

$$
\begin{aligned}
& \text { A: Spr spr } \\
& \text { B: Cal spp } \\
& \text { C: Gob spp } \\
& \text { D: Amm spp } \\
& \text { E: Tra tra } \\
& \text { F: Bug lut } \\
& \text { G: Lim lim } \\
& \text { H: Sol sol } \\
& \text { I: Mer mer } \\
& \text { J: Clu har }
\end{aligned}
$$

Figure 2: Larval abundances (ind.100m ${ }^{-3}$, log-transformed) by year (top) and month (bottom). Numbers inside the box plots are the proportions (\%). For each plot, only the taxa accounting for $80 \%$ of the cumulative abundance are represented. Taxa abbreviations are given in Table 2. Note that March was only sampled in 2017 and June only in 1993 and 1994 (Table 1).

Differences in larval fish composition between months were also found. In March six taxa accounted for $80 \%$ of the total abundance (sprat, sandeels, dab, sole, herring and 
whiting). In April, five dominant taxa emerged: sprat, dragonets, sandeels, whiting and dab whereas in May sandeels were replaced by sole. In June, the number of dominant taxa decreased to three with sprat, horse mackerel and dragonets. Sprat was always the most abundant taxa regardless of the month with a proportion ranging from $29.2 \%$ in March to $53.9 \%$ in May.

A PCoA was performed on larval assemblages per station and survey (Figure 3). The first two axes explained $50 \%$ and $23 \%$ of the variability res oectively. The different surveys were distributed along the first axis with March 2017 on the ight the ones of April and May in the middle and the June surveys of 1993 and 1994 on the eft. Annual succession was also distributed along this axis with 1993 and 1994 ma nly on the left, 1995 and 1999 in the middle and 2017 on the right. On the second axis, April and May of the nineties were separated from the other surveys.

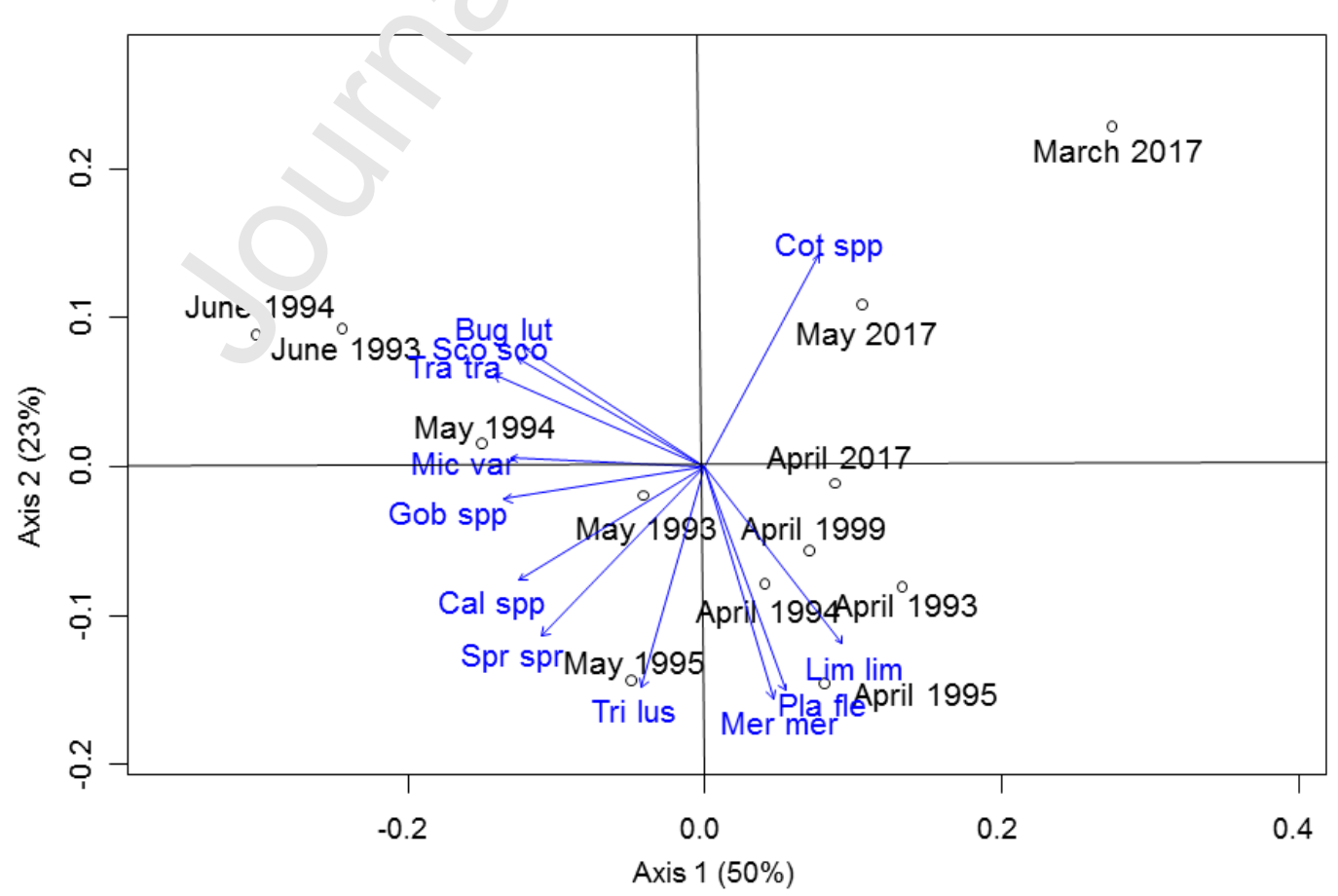


Figure 3: Principal coordinate analysis, factorial plane of the first two axes. Only taxa contributing significantly to the period separation along the axes are represented (permutation test, 999 permutations). Taxa abbreviations are given in Table 2. The barycentric position of each survey (indicated as month and year) is also represented.

All significant taxa, except cottids, were associated with, i.e. more abundant in, the nineties surveys. Dab, flounder and whiting were correlated with April surveys, thickback sole, gobies, dragonets, sprat and pouting with May surveys and solenette, mackerel and horse mackerel with June surveys.

A Pearson correlation test performed on the set $v^{\text {s }}$ environmental and geographical variables revealed a strong correlation between latitude . nd bedstress $\left(\mathrm{R}^{2}=0.61 ; \mathrm{F}\right.$-statistic: 159.7; $\left.\mathrm{p}<2.2 \mathrm{e}^{-16}\right)$, and latitude was therefore remover, $\mathrm{n}>\mathrm{m}$ further analyses.

Results of the OMI analysis built ıno. the PCA on environmental factors, selected by the correlation test, and the fauna matr ${ }_{\mathrm{L}}$ were used to explore fish larval environmental preferences and dependencies (Figr $\ldots 4$, The total inertia represented $60 \%$ of the fauna matrix variation. Both axes hac a cumulative projected inertia of $86 \%$ (53\% and 33\% respectively). The total numbe: oi taxa was related to depth and distance to the coast and not correlated with temperat ie. Most of the taxa were related with these geographical variables and low temperatures wh reas solenette, mackerel, horse mackerel and lesser weever were related with high temperatures. Plaice and flounder appeared corelated with stations far from estuaries with low temperatures. 


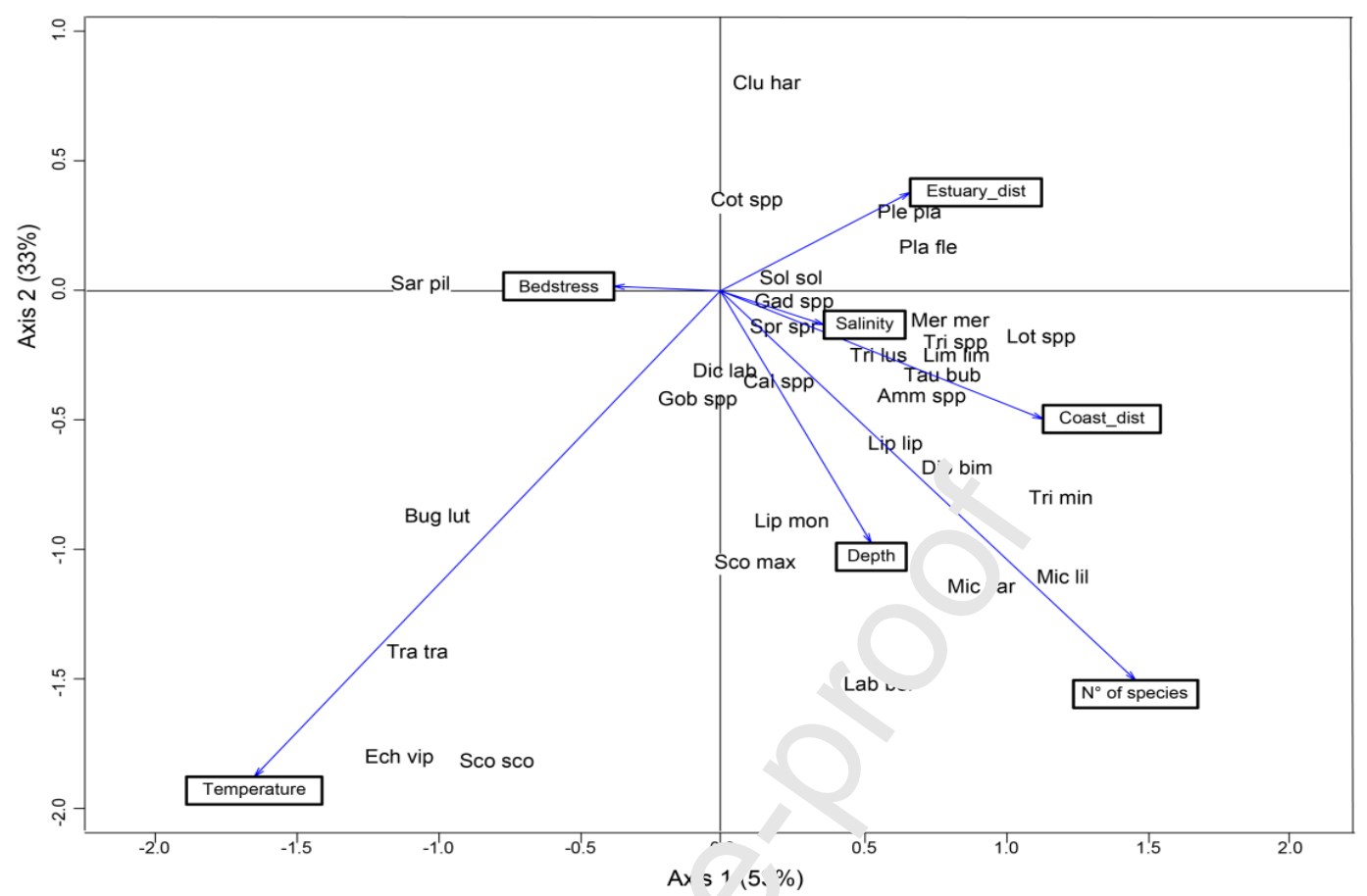

Figure 4: OMI analysis: scatter plot of t ief rst two axes. Arrow lengths represent the quality of representation of variables in boxes. Tas. abbreviations are given in Table 2. Note that all surveys we. included in the analysis.

OMI and tolerance valles vere obtained (Figure 5). OMI values ranged from 0.06 (sprat) to 4.85 (lesser weev $r$ ). the Monte Carlo permutation test showed that sea bass, twospotted clingfish and $\mathrm{o}^{2}$ - (other than whiting, pouting and poor cod) were not influenced by the set of variables used for the analysis. Sprat, sole, dragonets, gobies, pouting, whiting and sandeels had the lowest OMI values and high tolerance values, indicating ubiquitous taxa. Conversely, several taxa including lesser weever, mackerel, horse mackerel, sardine, wrasses, snailfishes and poor cod had the highest OMI values and lower tolerance values indicating specialist taxa. Other taxa such as cottids and solenette had intermediate OMI and tolerance values, characteristic of neither specialist nor generalist taxa. 


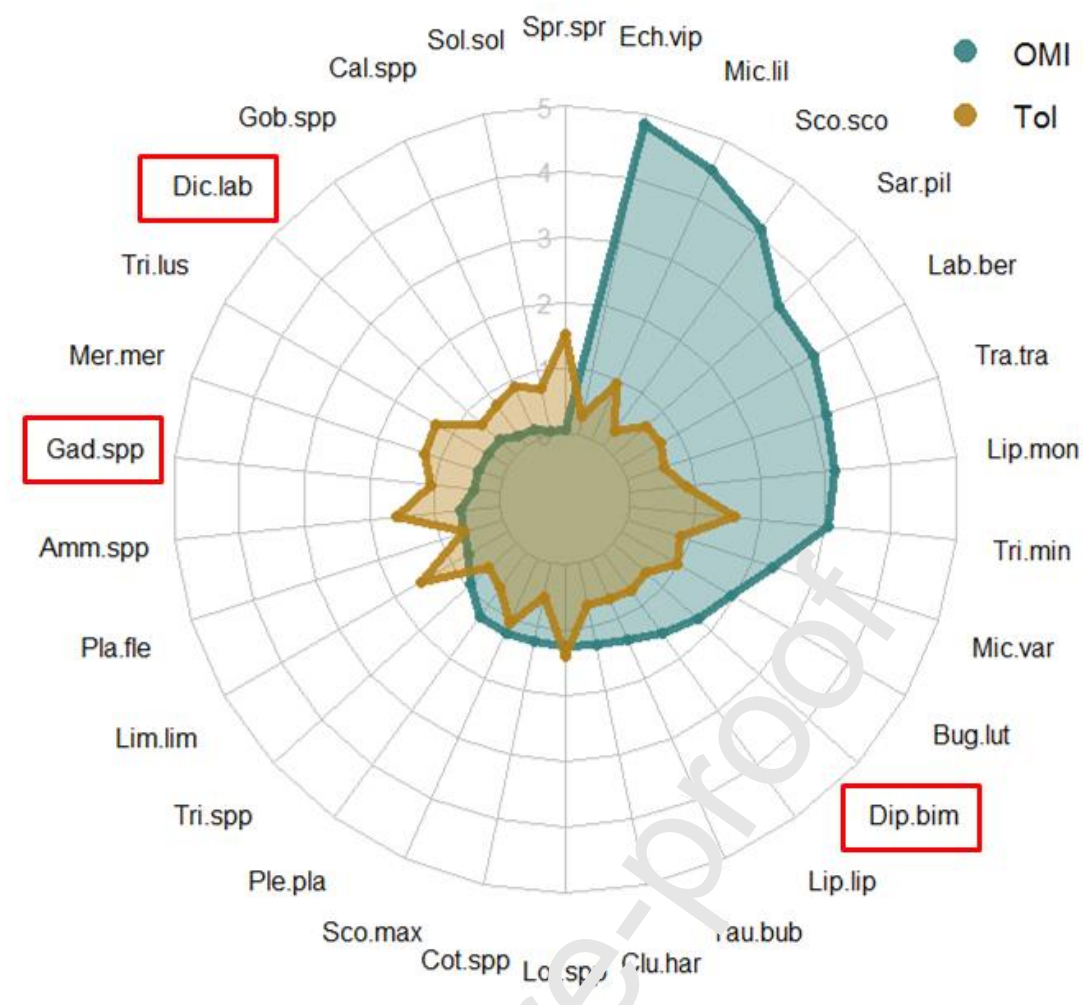

Figure 5: radarchart of OMI (mar si ia ¿iy) and tolerance (Tol) values for the 30 taxa. Red boxes show non-signific an. taxa. Taxa abbreviations are given in Table 2. 
Nine spatial $\left(R^{2} a d j=0.104\right)$, six seasonal $\left(R^{2} a d j=0.309\right)$ and four annual $\left(R^{2} a d j=\right.$ 0.158) variables were kept at the end of the MEM analysis. The variation partitioning results (Figure 6) indicated that $44 \%$ of the total variation was explained, $33 \%$ by the seasonal effect, $16 \%$ by the year effect, $10 \%$ by the spatial effect and $13 \%$ by the environmental effect. In terms of pure effect, season explained the most (12\%) followed by space (5\%), environment (3\%) and year (2\%). A large amount of variation was shared between the different variables, in particular between year and season (8\%) and season and environment (7\%), while environment and year shared no variation, and environment and $\mathrm{sp}_{\mathfrak{c}} \mathrm{e}$ only $1 \%$.

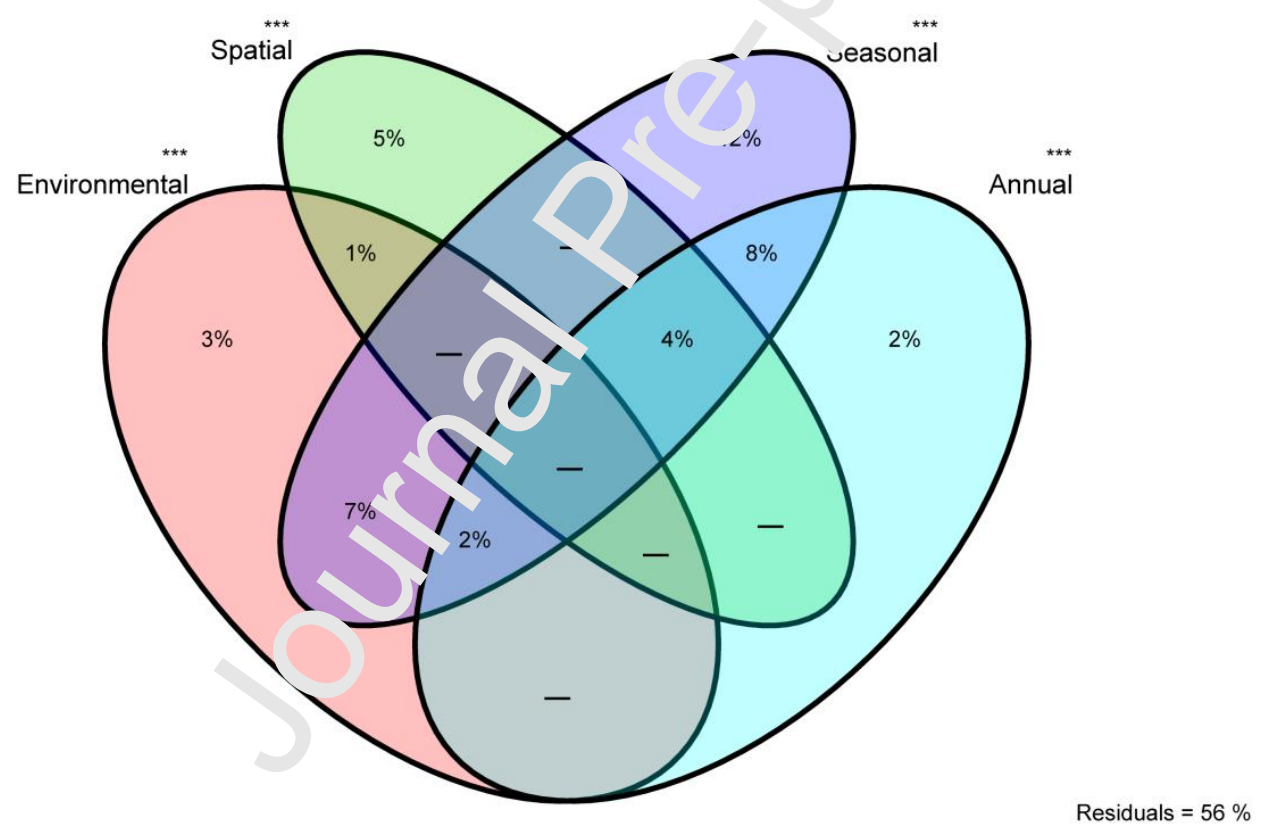

Figure 6: Variance partitioning analysis. Venn diagram showing the percentage of variation explained in the larval assemblages by each of the spatial, environmental, seasonal and annual effects. ***: p-value $<0.001$. Note that all surveys were included in the analysis. 


\section{Discussion}

The contribution of different sources of variation including environment, year, season and geography on spring larval assemblages in the EEC was investigated. Whereas the present study area pertains to a limited part of the English Channel, the eastern part provides important spawning and nursery areas for many species (Carpentier et al., 2009; Eastwood et al., 2003). This paper gives an update on the seasonal succession of the main larval fish species encountered in spring. It appeared that the year and seasonal effects linked to environmental conditions were the main drivers ex slaing the observed variation whereas the spatial effect did not substantially change bet vee the nineties and 2017. OMI analysis revealed that the number of species was prsineiy correlated with the distance to the coast and depth. This could stem from the frc ntal cone impact on larval assemblages well described by Grioche and Koubbi $\left(19^{\prime} /\right.$ ) and Grioche et al. (1999) who showed a spatial segregation of fish larvae assemu:- ges between coastal and central waters in the south of the EEC due to a frontal zone a ting more or less as a permeable barrier (depending on the tidal regime). This spati a pauern is accentuated by the ontogenetic migration of several larval species from ho offshore spawning grounds towards coastal nurseries (Grioche et al., 2001; K n'b et al., 2006). However, the variance partitioning analysis also revealed that this spatial . ffect only accounted for $10 \%$ of the explained variation, which is fairly low compared to inter-annual and seasonal effects.

A temporal succession of larval taxa was observed during spring. Of the ten dominant taxa that were identified, some were characteristic of a particular month (e.g. herring in March, horse mackerel in June) whereas others were dominant throughout the season (i.e. sprat). This temporal pattern can be explained by fish strategies in terms of spawning period, time duration of the larval development and foraging. Sprat was clearly the most abundant 
larval fish species in the EEC throughout the spring season, which is in accordance with its protracted reproductive season (Alheit, 1988). Sprat is a batch spawner and females can lay nine batches of eggs during the reproductive season. It is also the most abundant adult fish species (Vaz et al., 2007) in the EEC and recently reached a record abundance in the North Sea (ICES, 2018). Moreover, the OMI analysis revealed a low marginality and a high tolerance meaning that sprat larvae were ubiquitous and tolerate a high range of temperatures allowing an extended spawning period. These findings are in agreement with previous studies showing that viable eggs of sprat can be found at a wide ranoe $\mathrm{c}^{\mathrm{c}}$ temperatures from $2^{\circ} \mathrm{C}$ to $20^{\circ} \mathrm{C}$, although survival for North Sea sprat decreases at tf $1 \mathrm{II}$ ratures below $6^{\circ} \mathrm{C}$ (Thomson et al., 1981).

In March 2017, larval assemblages $\mathrm{w}^{\infty}=$ dommated by six taxa including, apart from sprat, a combination of larvae from wi ter spawners (e.g. herring, plaice) and earlyspring spawners (e.g. sole, dab, whiting). The presence of herring larvae is in accordance with the spawning time of the Do . s spawning component of North Sea herring, which hatches in the EEC mainly in D:ces.her-January (Corten, 2013; Heath et al., 1997). Plaice is also a winter spawning fis: and generally spawns in early January in the EEC (Fox et al., 2005).

In April and May, larval assemblages that were observed in the different years were dominated by five other taxa including sole, dab, whiting, sandeels and dragonets. Sandeels and whiting were more abundant in April contrary to sole and dab. Dragonets were abundant in both months. While they represented only $0.9 \%$ of the March assemblage, they became the second most abundant taxa in April (9.5\%) and May (12.5\%) and finally reached $16.1 \%$ in June. Hence dragonets, like sprat, were not specially affiliated to late spring conditions but were ubiquitous and supported a high range of temperatures. 
In June, larval assemblages were different compared to the earlier months. Apart from sprat and dragonets, horse mackerel was the second most abundant species and was associated with other less abundant species like lesser weever, solenette and mackerel in the OMI analysis. Their high marginality and low tolerance regarding temperature indicated a "warm water" affinity of these larvae hatching during late spring and early summer. Although, Russel (1976) and Clark (1920) reported that horse mackerel spawns in the EEC from July onwards, our results show that horse mackerel larvae can already be found in June suggesting that the spawning season may start errlic: than July.

In terms of inter-annual variations, our results fron the Kruskal-Wallis tests combined with those from PCoA clearly showed a significative dit rence in larval abundances for April and May in the southern part of the EEC ( $\operatorname{excer}_{\mathbf{r}}^{+}$between Boulogne sur Mer and Belgium) between 2017 and the nineties. Indeed, the ov rall abundance of the dominant taxa was more than two times lower during 2017 (even when only considering April and May that were sampled every year) compared to th - nim ties. In the PCoA all significant taxa (including both generalists and specialists), exceıt u vttids, were clearly more abundant during the nineties' surveys, suggesting changes is ha abundance of the main larval fish species of the EEC ecosystem. From the $\mathrm{K}\lrcorner$ usk $1-$ Wallis test, we also found more significant differences between 1999 and the early ninetie (at least in April) than with 2017. This suggests that changes in the level of larval abundances in the EEC might have already started at the end of the nineties.

With no shared variation between year and environment, temperature and salinity do not appear to be the only factors that could explain changes in larval assemblages. Auber et al. (2017) studied adult fish abundances in the EEC between 1980-1997 and 1998-2012. They showed a significant decrease of abundances in the recent period as we found with larval abundances. This was particularly the case for five taxa, namely sprat, dab, plaice, dragonets 
and gobies, which correspond to the larval taxa more associated with the nineties surveys in the PCoA. In agreement with our results, they found cottids to be one of the rare adult fish taxa more abundant in the 1998-2012 period. Adults of all the other taxa (except horse mackerel) were also less abundant during the 1998-2012 period (but this was not significant). Concerning horse mackerel, the discrepancy between larvae, more abundant during the nineties, and adults, more abundant in the recent period, is potentially due to the fact that in 2017 no survey was conducted in June whereas June has been shown to be relevant for larval occurrence of this species.

Auber et al. (2017) hypothesized that these chan $_{i}$ es setween the two periods were linked to the AMO, which reflects the variation o st surface temperature in the North Atlantic Ocean at a multidecadal scale. In the midie of the nineties, the EEC experienced an increase of temperature due to a shift from n $\mathrm{cu}^{\text {'d }}$ to a warm phase of the AMO (Drinkwater et al., 2014). In the English Channel, the AM!' and the Russell Cycle vary together (Edwards et al., 2013; Russell et al., 1971). The 'issull cycle is a well-known phenomenon illustrating the influence of climate variations ( $w$, rmı and cool conditions) on marine plankton at the decadal scale which leads to change in fish distribution and abundances. Even if the truly cyclical nature of planktonic cha tges is not proven, phase changes in major climatic cycles, such as the AMO, lead to variai ons in assemblages (McManus et al., 2016). A shift in 1998 in dinoflagellate and dominant zooplankton groups has been shown by Beaugrand (2003) and Alvarez-Fernandez et al. (2012) who established a link with a rapid change in environmental conditions. Several studies also found that plankton and fish larvae were more abundant during a cold period than during a warm period of the AMO (Alheit et al., 2014; Cushing and Dickson, 1976, Southward et al., 1988). Since fish larvae survival highly relies on food availability, it could have been impacted by recent changes in plankton communities, due to increasing surface temperature. Higher temperatures also enhance larval growth rates (Pepin, 
1991) which can in turn increase mortality due to starvation (Montero-Serra et al., 2015). Consequently, a lower survival rate during the larval phase could have led to fewer adults as observed by Auber et al. (2017). An alternative hypothesis is that lower larval abundance could come from a more northward distribution and spawning location in response to warming (Jansen and Gislason, 2011; Montero-Serra et al., 2014). While adults abundances of mainly small bodied species decreased drastically in the EEC (Aubert et al., 2017, McLean et al., 2018a) found a northward increase of these species in the connected ecosystem of the south bay of the North Sea that appeared simultaneously due to a rapid sea surface warming (McLean et al, 2018b). This hypothesis would mean ula the EEC's spawning potential rapidly declined during the climate oscillation of the end $\iota^{c}$ nineties.

\section{Conclusion}

Studying assemblage variation of ear y lic stages of fish is essential to understanding changes in fish population dynamics in the context of global change. The monthly succession of larval species remains the main o r $\mathrm{r}$ of variability in larval assemblages during spring in the EEC. However, the present sudy also showed lower abundances in 2017 compared to the nineties. This decrease apperea to be in line with observations on the adults in the same area. This clear decline in ?he GEr, does not necessarily mean that spawning populations are going down, but it would be worthwhile to investigate if the signal in a small part of the distribution area signifies a change in geographical distribution or indeed a decrease of the whole spawning population. The climatic regime shift could have led to a decrease in the larval survival rate and/or to a northward shift in the geographical distribution of adults, both leading to the observed decrease of the spawning population in the area and consequently in the number of fish larvae. Whereas these observations during one year will need to be 
confirmed through a multiannual sampling, they may reflect true changes, as they were also observed for phyto- and zooplankton communities as well as fish adults.

\section{Acknowledgments}

We would like to thank the Pôle Metropolitain de la Côte d'Opale and the SMAC (Sole de Manche Est) project (supported by France Filière Pêche and the Hauts-de-France region) for their financial support. Our acknowledgments are also dedicated to all persons involved in the three recent surveys, especially Eric Tavernier, Liq Joly, Romain Causse, Ugo Werner and Felipe Artigas as scientist in charge of the $\mathrm{PH}_{\mathbf{1}}^{\mathrm{r}} \mathrm{C}$, survey. Finally, we thank Matthew McLean who revised the English.

\section{References}

Alheit, J. (1988). Reproductive biology of nrat (Sprattus sprattus): factors determining annual egg production. ICES Journal of : Yar le Science 44(2), 162-168.

Alheit, J., Licandro, P., Coombs, S., Tarcia, A., Giráldez, A., Santamaría, M. T. G., ... and Tsikliras, A. C. (2014). Reprint $r^{\varepsilon}$ "tlantic Multidecadal Oscillation (AMO) modulates dynamics of small pelagic fishes ana cr system regime shifts in the eastern North and Central Atlantic". Journal of Marine Syst ms 133, 88-102.

Alvarez-Fernandez, S., Lindebu $>$ m, H., and Meesters, E. (2012). Temporal changes in plankton of the North Sea: c >mmunity shifts and environmental drivers. Marine Ecology Progress Series 462, 21-??.

Anderson, M.J., and C. 'bble, N.A. (1998). Partitioning the variation among spatial, temporal and environmental com $_{1}^{\sim}$ nents in a multivariate data set. Australian Journal of Ecology 23, $158-167$.

Auber, A., Travers-Trolet, M., Villanueva, M.C., and Ernande, B. (2015). Regime shift in an exploited fish community related to natural climate oscillations. PLOS ONE 10, e0129883.

Auber, A., Gohin, F., Goascoz, N., and Schlaich, I. (2017). Decline of cold-water fish species in the Bay of Somme (English Channel, France) in response to ocean warming. Estuarine, Coastal and Shelf Science 189, 189-202.

Baho, D.L., Futter, M.N., Johnson, R.K., and Angeler, D.G. (2015). Assessing temporal scales and patterns in time series: Comparing methods based on redundancy analysis. Ecological Complexity 22, 162-168. 
Beaugrand, G. (2003). Long-term changes in copepod abundance and diversity in the northeast Atlantic in relation to fluctuations in the hydroclimatic environment. Fisheries Oceanography 12, 270-283.

Blanchet, F.G., Legendre, P., and Borcard, D. (2008). Forward selection of explanatory variables. Ecology 89, 2623-2632.

Borcard, D., and Legendre, P. (2002). All-scale spatial analysis of ecological data by means of principal coordinates of neighbour matrices. Ecological Modelling 153, 51-68.

Brylinski, J.-M., and Lagadeuc, Y. (1990). L'interface eaux côtières/eaux du large dans le Pas-de-Calais (côte française): une zone frontale. Comptes rendus de l'Académie des sciences. Série 2, Mécanique, Physique, Chimie, Sciences de l'univers, Sciences de la Terre $311,535-540$.

Carpentier, A., Martin, C. S., Vaz, S., Coppin, F., Curet, L., Na 'vin, J. C., ... \& Ernande, B. (2009). The Channel habitat atlas for marine resource man a nent (CHARM): an aid for planning and decision-making in an area under strong ar hroj ogenic pressure. Aquatic Living Resources 22(4), 499-508.

Clark, R.S. (1920). The pelagic young and early ottr $m$ stages of teleosteans. J. Mar. Biol.Assoc. 12, 152-240.

Corten, A. (2013). Recruitment depressions in N th Sea herring. ICES J Mar Sci 70, 1-15.

Cushing, D.H., and Dickson, R.R. $\left(19^{\prime}, 6\right)$ The biological response in the sea to climatic changes. Advances in Marine Biology 14, 122.

Dickey-Collas, M., Bolle, L.J., Beek, J.' L. van, and Erftemeijer, P.L.A. (2009). Variability in transport of fish eggs and larvae. J. Lffects of hydrodynamics on the transport of Downs herring larvae. Marine Ecology P os - ess Series 390, 183-194.

Dolédec, S., Chessel D., an ₹ ₹imaret-Carpentier C. (2000). Niche separation in community analysis: a new method. Ecrlogy 81, 2914-2927.

Dray, S., Legendre, P., anc Peres-Neto, P.R. (2006). Spatial modelling: a comprehensive framework for principai coordinate analysis of neighbour matrices (PCNM). Ecological Modelling 196, 483-49?

Drinkwater, K.F., Miles, M., Medhaug, I., Otterå, O.H., Kristiansen, T., Sundby, S., and Gao, Y. (2014). The Atlantic Multidecadal Oscillation: Its manifestations and impacts with special emphasis on the Atlantic region north of $60^{\circ} \mathrm{N}$. Journal of Marine Systems 133, 117-130.

Edwards, M., Beaugrand, G., Helaouët, P., Alheit, J., and Coombs, S. (2013). Marine ecosystem response to the Atlantic Multidecadal Oscillation. PLOS ONE 8, e57212.

Eastwood, P.D., Meaden, G.J., Carpentier, A., and Rogers, S.I. (2003). Estimating limits to the spatial extent and suitability of sole (Solea solea) nursery grounds in the Dover Strait. Journal of Sea Research 50, 151-165. 
Fox, C.J., Taylor, M., Dickey-Collas, M., Damme, V., G, C.J., Bolle, L.J., Daan, N., Rohlf, N., Kraus, G., Munk, P., et al. (2005). Initial results from the 2004 ichthyoplankton survey of the North Sea (ICES).

Grioche, A., and Koubbi, P. (1997). A preliminary study of the influence of a coastal frontal structure on ichthyoplankton assemblages in the English Channel. ICES J. Mar. Sci. 54, 93104.

Grioche, A., Koubbi, P., and Harlay, X. (1999). Spatial Patterns of Ichthyoplankton Assemblages Along the Eastern English Channel French Coast during Spring 1995. Estuarine, Coastal and Shelf Science 49, 141-152.

Grioche, A., Harlay, X., Koubbi, P., and Lago, L.F. (2000). Vertical migrations of fish larvae: Eulerian and Lagrangian observations in the Eastern English Channel. J. Plankton Res. 22, 1813-1828.

Grioche, A., Koubbi, P., Harlay, X., and Sautour, B. (2001, sole larval distribution (Solea solea) in the eastern English Channel and Southern Bigh of the North Sea. Journal of the Marine Biological Association of the United Kingdom $\mathcal{E}, 6 / 2-678$.

Gross, J. (2003). Variance inflation factors. R News s, 1). 3-15.

Hawkins, S. J., Firth, L. B., McHugh, M., Poloc al 'ka, E. S., Herbert, R. J. H., Burrows, M. T., ... and Sims, D. W. (2013). Data rescue a nu re use: recycling old information to address new policy concerns. Marine Policy 42, 9,,-28 .

Heath, M., Scott, B., and Bryant, A.D. (:997). Modelling the growth of herring from four different stocks in the North Sea. Joun..1 of Sea Research 38, 413-436.

Hollander, M., and Wolfe, D. A. (1'77). Nonparametric statistical procedures. New York: Willey.

Houde, E. D., and Hoyt, n. D. (1987). Fish early life dynamics and recruitment variability. Trans. Am. Fish Soc.

ICES. (2018). Report of the Herring Assessment Working Group for the Area South of $62^{\circ} \mathrm{N}$ (HAWG). 29-31 Janua, ¿U18 and 12-20 March 2018. ICES HQ, Copenhagen, Denmark. ICES CM 2018/ACOM. $\sim 960$ pp

James, G., Witten, D., Hastie, T., and Tibshirani, R. (2013). An Introduction to Statistical Learning: with Applications in R (New York: Springer-Verlag).

Jansen, T., and Gislason, H. (2011). Temperature affects the timing of spawning and migration of North Sea mackerel. Continental Shelf Research 31, 64-72.

Koubbi, P., Loots, C., Cotonnec, G., Harlay, X., Grioche, A., Vaz, S., Martin, C.C.C.U., Walkey, M., and Carpentier, A. (2006). Spatial patterns and GIS habitat modelling of Solea solea, Pleuronectes flesus and Limanda limanda fish larvae in the eastern English Channel during the spring. Scientia Marina 147-157.

Legendre, P., and Legendre, L.F.J. (2012). Numerical Ecology (Elsevier). 
Loots, C., Vaz, S., Planque, B., and Koubbi, P. (2010). What controls the spatial distribution of the North Sea plaice spawning population? Confronting ecological hypotheses through a model selection framework. ICES J Mar Sci 67, 244-257.

McLean, M., Mouillot, D., Lindegren, M., Engelhard, G., Villéger, S., Marchal, P., Brind'Amour, A., and Auber, A. (2018a). A Climate-Driven functional inversion of connected marine ecosystems. Current Biology 28, 3654-3660.e3.

McLean, M.J., Mouillot, D., Goascoz, N., Schlaich, I., and Auber, A. (2018b). Functional reorganization of marine fish nurseries under climate warming. Global Change Biology 25(2), 660-674.

McManus, M.C., Licandro, P., and Coombs, S.H. (2016). Is the Russell Cycle a true cycle? Multidecadal zooplankton and climate trends in the western Erglish Channel. ICES J Mar Sci 73, 227-238.

Miller, B., and Kendall, A.W. (2009). Early life history of narine fishes (University of California Press).

Miller, J.K., and Farr, S.D. (1971). Bimultivariate red'nncy: a comprehensive measure of interbattery relationship. Multivariate Behavioral Res arcl 6, 313-324.

Montero-Serra, I., Edwards, M., and Genner, Iv ... (2015). Warming shelf seas drive the subtropicalization of European pelagic fish $\mathrm{c} \mathrm{n}_{\mathrm{n}} \mathrm{n}^{\mathrm{n}}$.ities. Global Change Biology 21, 144153.

Mood, A. M. (1971). Partitioning varianc in multiple regression analyses as a tool for developing learning models. American Fducational Research Journal, 8(2), 191-202.

Pepin, P. (1991). Effect of temperaı e and size on development, mortality, and survival rates of the pelagic early life history sti ges of marine fish. Can. J. Fish. Aquat. Sci. 48, 503-518.

Peres-Neto, P.R., Legendre, D., Tray, S., and Borcard, D. (2006). Variation Partitioning of species data matrices: estim tion and comparison of fractions. Ecology 87, 2614-2625.

R Development Cc॰ Tea a (2008). R: A language and environment for statistical computing. R Foundation for Statistical Computing, Vienna, Austria.

Reid, P.C., Borges, M. de F., and Svendsen, E. (2001). A regime shift in the North Sea circa 1988 linked to changes in the North Sea horse mackerel fishery. Fisheries Research 50, 163171.

Russell, F.S. (1976). The eggs and planktonic stages of British marine fishes.

Russell, F.S., Southward, A.J., Boalch, G.T., and Butler, E.I. (1971). Changes in biological conditions in the english channel off plymouth during the last half century. Nature 234, 468470 .

Smith, P. E. (1977). Standard techniques for pelagic fish egg and larva surveys. FAO Fish. Tech. Pap. 175, 1-100. 
Somarakis, S., Tsoukali, S., Giannoulaki, M., Schismenou, E., and Nikolioudakis, N. (2018). Spawning stock, egg production and larval survival in relation to small pelagic fish recruitment. Marine Ecology Progress Series.

Southward, A.J., Boalch, G.T., and Maddock, L. (1988). Fluctuations in the herring and pilchard fisheries of Devon and Cornwall linked to change in climate since the 16th century. Journal of the Marine Biological Association of the United Kingdom 68, 423-445.

Thompson, B. M., Milligan, S. P., and Nichols, J. H. (1981). The development rates of sprat (Sprattus sprattus L.) eggs over a range of temperatures.

Vaz, S., Carpentier, A., and Coppin, F. (2007). Eastern English Channel fish assemblages: measuring the structuring effect of habitats on distinct sub-communities. ICES J Mar Sci 64, 271-287. 


\section{Declaration of interests}

$\bigotimes$ The authors declare that they have no known competing financial interests or personal relationships that could have appeared to influence the work reported in this paper.

$\square$ The authors declare the following financial interests/personal relationships whi ch may be considered as potential competing interests: 


\section{Highlights}

Larval assemblages were dominated by ten species

Overall abundances and diversity increased across the spring season

Larval abundances were significantly lower in 2017 compared to the nineties

Several larval and adult fish species responded similarly to a shift in the AMO 